\title{
Determinantes das Exportações Agropecuárias Brasileiras e sua Relação com o Investimento Direto Estrangeiro*
}

\section{Determinants of Brazilian Agricultural Exports and lts Relationship with Foreign Direct Investment}

\author{
Geraldo Moreira Bittencourt** \\ Antônio Carvalho Campos***
}

\begin{abstract}
Resumo: O presente estudo tem como objetivo avaliar as relações de interdependência entre as exportações agropecuárias brasileiras, o investimento direto estrangeiro no setor agroexportador, a renda mundial e a taxa de câmbio, além de verificar quais dessas variáveis realmente têm influenciado o desempenho das exportações agrícolas do Brasil. Para tanto, estimou-se um modelo VAR padrão, a partir do qual foi realizado o teste de causalidade de Granger e a decomposição da variância do erro de previsão. A análise dos resultados mostra que a renda externa representa parte importante da variância das exportações agropecuárias brasileiras, o IDE no setor não obteve participação relevante e a variável câmbio, por meio de seus efeitos sobre a renda mundial, apresentou influência indireta sobre as exportações agrícolas. Tais resultados convergem para a importância de se direcionar o ingresso de capital estrangeiro, no setor agropecuário, para a criação de infraestrutura e novas unidades produtivas, não deixando que a entrada de investimento externo nesse setor continue se caracterizando como um processo de internacionalização da produção de certas cadeias agroindustriais.
\end{abstract}

Palavras-chave: Exportações. Investimento direto estrangeiro. Agronegócio.

Abstract: The present study aims to evaluate the relationship of interdependence between the Brazilian agricultural exports, foreign direct investment in the agricultural export sector, world income and the exchange rate, and to identify which of these variables has really influenced the performance of Brazil's agricultural exports. For this, we estimated a standard VAR model, from which was conducted the Granger Causality Test and the variance decomposition of forecast error. The analysis shows that the foreign income is an important part of the variance of the Brazilian agricultural exports, FDI in the sector has not obtained a relevant participation and that the exchange rate variable, through their effects on foreign income, had an indirect influence on agricultural exports. These results converge on the importance of direct foreign capital inflow, in the agricultural sector, be directed to create infrastructure and new production units, not

* Os autores agradecem os comentários dos pareceristas anônimos.

** Doutorando em Economia Aplicada pela Universidade Federal de Viçosa (UFV). Professor do Departamento de Economia da Universidade Federal de Juiz de Fora/Campus Governador Valadares (UFJF/GV). E-mail: geraldo.bittencourt@ufjf.edu.br

*** Pós-doutor pela Purdue University, EUA. Professor-titular do Departamento de Economia Rural da UFV. E-mail: accampos@ufv.br 
allowing that the entry of foreign investment in this sector continues to be characterized as a process of internationalization of production of certain agroindustrial chains.

Keywords: Exports. Foreign direct investment. Agribusiness.

JEL Classification: Q17; F21.

\section{Introdução}

No Brasil, a década de 1980, caracterizada pela crise da dívida, baixo crescimento econômico e alta inflação, foi marcada por uma considerável redução do fluxo de investimento direto estrangeiro (IDE). Por outro lado, a abertura comercial da economia, as privatizações e a eliminação de diversos incentivos à produção doméstica foram usadas, na década de 1990, como instrumentos de política industrial e comercial para corrigir distorções na alocação de recursos do país. Além disso, o surgimento das grandes multinacionais de processamento de alimento e varejo, frente ao processo de globalização econômica, também contribuiu para uma nova elevação do ingresso de investimento estrangeiro no mercado brasileiro (CHADDAD et al., 2006).

No entanto, tais procedimentos e medidas, combinados com a apreciação do câmbio a partir do Plano Real, inverteram o superávit comercial brasileiro de aproximadamente US\$ 15,3 bilhões, em 1992, em um déficit de US\$ 5,6 bilhões em 1996. Nos anos de 1990, o déficit comercial atingiu seu ápice em 1998 (US\$ 7 bilhões), e a conta-corrente do balanço de pagamentos como um todo revelou um saldo negativo de US\$33 bilhões nesse mesmo ano (BRASIL, 2011).

No ano de 1999, a adoção do câmbio flutuante evidenciou a disposição governamental em promover um ajuste na conta-corrente brasileira. Esperava-se que o saldo comercial, até então negativo, se revertesse, o que de fato aconteceu em 2001, revelando uma recuperação lenta e gradual (BANCO CENTRAL DO BRASIL, 2011).

Somente a partir de 2003, as exportações iniciaram uma trajetória mais consistente de expansão, embora o câmbio enfrentasse apreciação real. Naquele ano, a conta-corrente foi superavitária, o superávit comercial foi de US\$24 bilhões. Em 2004, esse superávit cresceu ainda mais, atingindo US\$ 33 bilhões. De 2002 a 2004, as exportações brasileiras registraram uma taxa de expansão de aproximadamente 60\%, bem acima da média mundial (42\%) (BANCO CENTRAL DO BRASIL, 2011).

Essa recuperação da balança comercial brasileira teve expressiva contribuição do agronegócio nacional, cujo saldo comercial do setor vem batendo constantes recordes desde 2000 e tornando-se o maior gerador de divisas, em termos líquidos, no saldo comercial do país. Segundo dados da Biblioteca Nacional de Agricultura (2010), no período de 1994 a 1999, as exportações agrícolas brasileiras cresceram abaixo do comércio agrícola mundial, devido, em especial, à aprecia- 
ção do câmbio no início do Plano Real e à conjuntura internacional desfavorável após 1997. Já entre 2000 e 2004, as exportações do setor mostraram um excelente desempenho, passando de US $\$ 15,4$ bilhões para US $\$ 30,8$ bilhões e registrando uma taxa anual de crescimento de $18,8 \%$. Mais que o dobro do crescimento do comércio agrícola mundial, que atingiu uma taxa anual de 9,1\%.

Segundo Oliveira (2007), a associação mais direta dessa expansão apresenta uma grande relação com a retomada do crescimento da economia mundial a partir de 2002, em que a liderança dos Estados Unidos com a absorção essencial de mercados produtores da Ásia, especialmente o chinês, ampliou fortemente os preços e a demanda de commodities. Outras avaliações consideram que esse ciclo de preços e comércio alterou decisivamente a inclusão de países exportadores de commodities primárias, que, adquirindo superávits comerciais mais persistentes diante do concomitante ciclo de liquidez internacional, apresentariam melhor avaliação de risco e atrairiam capitais de melhor qualidade (INTERNATIONAL MONETARY FUND, 2008).

De acordo com Markawald e Ribeiro (2005), outros analistas apontaram uma reação defasada das exportações à desvalorização de 1999. Esse argumento perde força com a continuidade do crescimento das exportações com apreciação cambial real, porém uma explicação adicional é que elevações, mesmo que transitórias, no nível da taxa de câmbio real, como as observadas em 1991, 1992, 1999, 2001 e 2002, podem ter contribuído para um aumento duradouro do número de empresas voltadas para exportação. Isso ocorreria caso a depreciação elevasse a rentabilidade esperada da atividade exportadora por um período de tempo suficiente para um aumento relevante da base de oferta exportadora. Porém, não há fortes evidências empíricas sobre isso.

Adicionalmente, deve-se destacar a relevante influência da expansão do ingresso de IDE na economia brasileira na década de 1990. Partindo de uma média de menos de US $\$ 2$ bilhões anuais no início dos anos de 1990, o Brasil passou a receber um volume crescente de investimentos, culminando com um valor de quase US $\$ 33$ bilhões de dólares, em 2000, e atingindo seu recorde no acumulado de janeiro a setembro de 2011, quando somou US $\$ 50,4$ bilhões (BANCO CENTRAL DO BRASIL, 2011).

Dados do Banco Central do Brasil mostram que, em relação ao setor agroalimentar, o total de IDE entre os anos de 2001 e 2004 chegou a US\$ 8,2 bilhões. Nesse contexto, setores como os de alimentos, papel e celulose, fumo e outros importantes do agronegócio apresentaram saldo comercial elevado desde a década de 1990 e, ao mesmo tempo, receberam grande volume de IDE no período.

No entanto, nos últimos anos, a entrada de capital estrangeiro no agronegócio brasileiro tem-se caracterizado, em grande parte, como um processo de internacionalização da produção de certas cadeias produtivas. Desse modo, no caso 
do setor sucroalcooleiro, os efeitos do investimento estrangeiro podem ser melhor mensurados pela capacidade de moagem das usinas controladas por capital não brasileiro, que saltaram de $7 \%$, em 2008, para $14 \%$, em 2009, 22\%, em 2010, e, finalmente, 32\% em 2011 (GUEDES, 2012).

Ainda segundo Guedes (2012), que também analisou as estratégias dos investidores no setor sucroalcooleiro, na maioria das vezes os investidores optaram mais por comprar usinas ou compartilhar o seu controle do que montar novas indústrias. Essas constatações levam a constantes indagações na literatura econômica a respeito da influencia do IDE na balança comercial brasileira.

Diante desse cenário, a questão que surge é a seguinte: o ingresso de investimento externo no setor agroexportador brasileiro demonstrou-se significativo para a explicação da expansão das exportações do setor? Ou seja, será que o IDE realmente tem contribuído para a geração de vantagens competitivas para os produtos exportáveis do agronegócio nacional? Quais as variáveis que realmente têm influenciado o desempenho das exportações agrícolas do Brasil?

A hipótese que permeia este trabalho é a que os fluxos de IDE, no setor agropecuário do Brasil, não geraram aumentos na competitividade e na capacidade de exportação de produtos do agronegócio brasileiro, tratando-se, muito mais, de um processo de transferência patrimonial. Além disso, é razoável supor que o crescimento da economia mundial, na última década, seja o principal contribuinte para a elevação dessas exportações.

Muitos estudos na área de comércio internacional, como os de Lima Junior (2005) e Flach (2006), têm buscado analisar o que determina a entrada de capital estrangeiro em cada país e têm deixado de avaliar o que eles realmente têm gerado para os distintos setores das economias receptoras. Sendo assim, este trabalho contribui com a literatura ao verificar, empiricamente, em que medida o IDE tem afetado o desempenho das exportações agropecuárias brasileiras, além de avaliar a participação da renda mundial e da taxa de câmbio.

O artigo está estruturado em outras cinco seções, além desta introdução: a segunda seção apresenta uma discussão teórica que fundamenta a pesquisa; a terceira aborda uma revisão de literatura; a quarta descreve o método e os dados utilizados; a quinta expõe os resultados; e, por fim, a última seção traz as considerações finais do trabalho.

\section{Referencial Teórico}

As teorias ligadas ao comércio internacional iniciaram-se com a teoria da vantagem absoluta de Adam Smith, o princípio das vantagens comparativas de David Ricardo e com a teoria neoclássica da dotação relativa de fatores desenvolvida pelos economistas suecos Eli Filip Hecksher e Bertil Ohlin. No entanto, de 
acordo com Nakano (1994), novas teorias do comércio colocaram em cheque as hipóteses neoclássicas, como concorrência perfeita, retornos constantes à escala e informação completa, e desenvolveram explicações dos padrões de comércio internacional a partir das interações estratégicas das empresas e dos governos.

Nesse sentido, o comercio mundial deixa de ser explicado essencialmente pela disponibilidade de fatores e passa a ser visto como resultado das decisões premeditadas das corporações e das políticas, ou seja, o comércio entre nações pode ser afetado tanto por fatores macroeconômicos (taxa de câmbio, renda doméstica e mundial, incidência de tributos, taxa de juros, investimento interno e externo, entre outros), quanto por fatores estruturais (infraestrutura, tecnologia, política comercial, etc.).

Segundo Oliveira (2007), a visão macroeconômica é de grande importância para se avaliar o desempenho das exportações, utilizando-se, principalmente, o câmbio real e a renda externa como alguns dos determinantes das exportações. $\mathrm{O}$ uso dessas variáveis baseia-se em equações teóricas de oferta da firma e demanda do consumidor quando os produtos negociados internacionalmente são finais, ou de oferta da firma e demanda de outra firma quando os produtos negociados são intermediários.

Ainda de acordo com Oliveira (2007), as especificações para a quantidade demandada quase sempre se justificam por estarem em conformidade com a teoria do consumidor. Se o consumidor maximiza a utilidade sujeita a uma restrição orçamentária, então as funções de demanda resultantes por exportações e importações representam, dada sua simetria num modelo de dois países e o ajuste pela taxa de câmbio, as quantidades demandadas como função do nível de renda da região que importa do preço do próprio bem importado e do preço dos substitutos domésticos.

As variáveis de política econômica, principalmente a cambial e fiscal (subsídios), também podem ser usadas como mecanismos de aumento da competitividade das exportações, sendo a taxa de câmbio real um instrumento bastante empregado para avaliar o desempenho exportador (PINHEIRO; HORTA, 1992). Para Bielschowsky e Stumpo (1996), em curto prazo, a variável crucial do comércio internacional continua sendo a taxa de câmbio, plano em que sobram divergências dentro e fora dos governos.

Para Cavalcanti e Ribeiro (1998), sendo a comparação entre os rendimentos nos mercados externo e interno feita em unidade monetária similar, a volatilidade e o nível da taxa real de câmbio determinam respectivamente a variância e o valor esperado da remuneração relativa das exportações. Dessa forma, a taxa real de câmbio afeta não só as exportações em curto prazo, mas também as decisões de investimento em atividades exportadoras. 
Os investimentos em fatores estruturais, como em infraestrutura e tecnologia, exercem grande influência no desempenho do setor exportador de cada país. Nesse sentido, o IDE também pode exercer influência positiva sobre o comércio exterior.

De acordo com Dunning (1988), o investimento externo pode ser classificado em quatro tipos. O primeiro tipo é denominado resource seeking, cujos investimentos geram pouco vínculo com o país receptor, pois visam aquisições de recursos, a baixos custos, para a produção de bens, porém, por ouro lado, contribuem para aumentar o fluxo de exportação.

O segundo tipo, denominado de market seeking, corresponde a um processo de aprendizagem para ajustar a tecnologia recebida da matriz às particularidades do mercado local e das exigências do governo regional. Dessa forma, o objetivo das corporações qualificadas nesse grupo é oferecer bens e serviços para o mercado interno do país no qual elas se instalam.

Já o terceiro tipo de investimento, asset seeking, é caracterizado pelo fato de concentrar-se na compra de empresas existentes. Segundo Fernandes (2006), isso foi o que aconteceu na década de 1990, quando a entrada de IDE se concentrou principalmente na forma de fusões, aquisições e joint-ventures ocorridas entre as grandes empresas globais.

Por último, o quarto tipo é a estratégia efficiency seeking, que objetiva o aproveitamento do mercado doméstico, procurando a obtenção de economias de escala e especialização intracorporação.

Com o intuito de ajustar a teoria do comércio internacional a essa teoria do IDE, que até a década de 1980 eram analisadas separadamente, surgem autores como Hirsch (1976), que buscaram traçar uma ligação entre comércio e investimento estrangeiro. O modelo de Hirsch parte da verificação de que, sobre os pressupostos neoclássicos, só haveria lugar para o IDE se houvesse diferencial de taxas de juros. No entanto, na presença desse diferencial, possivelmente prevaleceriam os investimentos em carteira e o crédito internacional. Sendo assim, Hirsch adiciona novos pressupostos no modelo para que o IDE seja viável. Esses pressupostos tratam da existência de funções e custos de produção distintos entre as nações, vantagens de algumas firmas, restrições à entrada e custos de organização de atividades internacionais das firmas.

Rugman et al. (1985), rearranjando o modelo de Hirsh (1976), enunciam que empresas que praticam IDE têm como alvo o mercado do próprio país de origem, aumentando, desse modo, o nível de exportações do país receptor. Outra forma pela qual o IDE colabora para o aumento na quantidade exportada, segundo Buckley e Casson (1981), é quando esses investimentos têm por objetivo a internalização de custos de transação, buscando minimizá-los. Farina e Viegas (2003) apontam que o fluxo de investimentos diretos para o setor de alimentos pode causar 
uma série de mudanças organizacionais e de estratégias dessas indústrias, representando, desse modo, um aumento da atividade exportadora.

Portanto, constata-se a existência de um importante debate teórico sobre as relações entre exportações e IDE, como também em relação às demais variáveis que impactam o comércio exterior de determinado país, o que evidencia uma diversidade de abordagens que consideram condições e pressupostos variados

\section{Revisão de Literatura}

No que tange às evidências empíricas, os estudos que analisam as relações entre as exportações e seus determinantes apresentam diferentes abordagens metodológicas e diferenciam-se, principalmente, quanto ao nível de agregação das variáveis.

Em um nível mais agregado dos dados, Rodrigues, Reis e Mattos (2012) examinaram a relação causal entre crescimento econômico (PIB), exportações totais e IDE no Brasil, durante o período que compreendeu os anos de 1947 a 2010. Para tanto, estimaram um modelo vetorial autorregressivo (VAR) em primeira diferença, a partir do qual foi realizado o teste de causalidade de Granger entre as variáveis em estudo. Os resultados do trabalho evidenciaram uma relação unidirecional entre exportações e IDE, bem como entre IDE e PIB, indicando que o IDE pode ser considerado um mecanismo de efeito entre as exportações e o crescimento econômico.

Por outro lado, em uma análise mais desagregada, Lima Jr. e Jaime Jr. (2008) avaliaram, ao longo da década de 1990 até meados dos anos 2000, o desempenho do IDE, retratando o montante e o perfil desse tipo de investimento na economia brasileira e sua contribuição ao balanço de pagamentos e ao crescimento da economia. Os resultados obtidos pelos autores apontaram que a concentração dos investimentos externos no país foi através de fusões e aquisições, seja por meio da privatização dos serviços públicos, seja através da venda de empresas privadas locais. Além disso, também constataram, ao longo do período, uma crescente participação do setor de serviços como principal setor de atração ao capital estrangeiro.

Adicionalmente, analisando o setor agroexportador em específico, Procópio, Fernandes e Silva (2010) avaliaram as estratégias de filiais estrangeiras do setor do agronegócio brasileiro, buscando verificar se a acumulação de IDE contribuiu para o aumento das suas exportações. Para tanto, os autores utilizaram uma análise discriminante para os anos de 1995, 2000 e 2005 e constataram que a maior parte do fluxo de IDE destinou-se aos subsetores do agronegócio caracterizados pelo déficit e pelo baixo nível comercial com o exterior, o que levou os autores a 
concluir que o IDE não contribuiu efetivamente para a melhoria do desempenho exportador do agronegócio brasileiro no período analisado.

Seguindo o contexto do setor agropecuário, Silva, Ferreira e Araújo (2007) avaliaram em que medida as exportações agropecuárias brasileiras responderam a alterações da taxa de câmbio real e da renda mundial no período entre 1980 e 2006. O modelo de correção de erro vetorial (VEC) estimado pelos autores mostrou que os efeitos de curto prazo das variações cambiais e da renda mundial indicaram mudanças significativas nas exportações agropecuárias. Ademais, mediante uma análise VAR para o período de 2000 a 2006, Oliveira (2007) verificou os determinantes da competitividade das exportações brasileiras nos setores de fabricação de produtos alimentícios e bebidas, fabricação de produtos do fumo e fabricação de artefatos de couro. Desse modo, os resultados encontrados pela autora indicaram que o câmbio, a demanda externa setorial e a produtividade do trabalho foram importantes determinantes das exportações setoriais brasileiras analisadas.

Portanto, esta revisão bibliográfica deixa evidente a importância da análise setorial e das variáveis selecionadas neste estudo, que busca avaliar os determinantes das exportações agropecuárias brasileiras. Além disso, destaca-se a modelagem VAR como relevante instrumental econométrico para a análise proposta. Essa modelagem será descrita na seção a seguir.

\section{Referencial Analítico}

Com o objetivo de verificar as relações de interdependência e a direção da causalidade, no sentido de precedência temporal, entre as variáveis renda externa, taxa de câmbio, exportações e IDE, será adotado o seguinte procedimento: primeiramente, serão analisadas as propriedades das séries em estudo quanto à presença de raiz unitária, em que se verifica a ordem de integração das mesmas. Esse procedimento será realizado por meio do teste de raiz unitária Dickey-Fuller Aumentado (ADF). ${ }^{1}$ Em seguida, se as séries forem estacionárias em nível I (0), os testes de causalidade e decomposição da variância do erro de previsão serão testados no contexto de um modelo VAR em nível, ou seja, o procedimento padrão. Caso pelo menos uma série seja não estacionária, isto é, apresente ordem de integração superior a I (0), será testada a presença de cointegração por meio da abordagem VAR, de Johansen-Juselius (1990).

Segundo Enders (1995), para haver cointegração, todas as séries devem ser integradas de mesma ordem. Caso estas sejam integradas de diferentes ordens, não podem ser cointegradas.

$1 \quad$ Para mais detalhes acerca do teste de raiz unitária Dickey-Fuller aumentado (ADF), consultar Enders (1995). 
Finalmente, havendo cointegração entre as séries, a causalidade de Granger será testada pela aplicação do teste modificado de causalidade de Granger (que inclui um termo de correção de erro) no contexto de um modelo de correção de erro vetorial (VEC). Caso não haja relação de cointegração, a causalidade entre as séries será testada no contexto de um modelo VAR em diferenças. ${ }^{2}$

\subsection{Modelo Empírico}

Nas análises que incluem mais de uma série temporal, pode-se utilizar o modelo VAR. A principal vantagem no uso do VAR é que se trata de um modelo multivariado dinâmico que permite analisar a relação entre as variáveis ao longo do tempo, levando-se em consideração a interdependência destas. Outro fator importante é o fato de se pressupor que todas as variáveis no modelo são endógenas, eliminando, assim, a possibilidade do viés de simultaneidade.

Os modelos de autorregressão vetorial têm sido largamente utilizados na análise de questões macroeconômicas, surgindo como uma alternativa aos modelos de equações simultâneas. É uma abordagem que também tem sido utilizada em estudos relacionados à economia agrícola, podendo-se mencionar, nesse caso, Barros, Bacchi e Burnquist (2002), Schwants et al. (2009) e Oliveira (2007).

O modelo VAR, proposto por Sims (1980), é constituído de séries temporais, em que as variáveis dependentes estão em função de suas próprias defasagens e de outras variáveis. O modelo VAR pode ser especificado da seguinte forma:

$$
\begin{aligned}
& Y W_{t}=\Phi_{1}+\sum_{j=1}^{p} \beta_{j} E X P_{t-j}+\sum_{j=1}^{p} \gamma_{j} I D E_{t-j}+\sum_{j=1}^{p} \lambda_{j} Y W_{t-j}+\sum_{j=1}^{p} \delta_{j} E R_{t-j}+e_{1 t} \\
& E X P_{t}=\Phi_{2}+\sum_{j=1}^{p} \eta_{j} E X P_{t-j}+\sum_{j=1}^{p} \kappa_{j} I D E_{t-j}+\sum_{j=1}^{p} \psi_{j} Y W_{t-j}+\sum_{j=1}^{p} v_{j} E R_{t-j}+e_{2 t} \\
& I D E_{t}=\Phi_{3}+\sum_{j=1}^{p} \rho_{j} E X P_{t-j}+\sum_{j=1}^{p} \omega_{j} I D E_{t-j}+\sum_{j=1}^{p} \sigma_{j} Y W_{t-j}+\sum_{j=1}^{p} \theta_{j} E R_{t-j}+e_{3 t} \\
& E R_{t}=\Phi_{4}+\sum_{j=1}^{p} \mu_{j} E X P_{t-j}+\sum_{j=1}^{p} \pi_{j} I D E_{t-j}+\sum_{j=1}^{p} \varphi_{j} Y W_{t-j}+\sum_{j=1}^{p} \tau_{j} E R_{t-j}+e_{4 t}
\end{aligned}
$$

em que YW representa a renda mundial (as importações somadas às exportações mundiais foram utilizadas como proxy para renda mundial), EXP refere-se às exportações agropecuárias brasileiras, IDE corresponde ao ingresso de IDE no setor agropecuário brasileiro, ER representa a taxa de câmbio, $p$ corresponde ao número de defasagens e $e_{n t}$ é o termo de erro estocástico da equação $n$ no tempo $t$.

Para selecionar o melhor modelo VAR, têm-se como base os critérios de Schwarz (SC), Akaike (AIC), Hannan Quinn (HQ), Likelihood ratio (LR) e o Final

2 Para mais detalhes acerca do teste de cointegração e do modelo VAR/VEC, consultar Enders (1995) e Bueno (2008). 
prediction error (FPE), os quais são importantes para determinar o número de defasagens a incluir na modelagem. Desse modo, a escolha do número de defasagens é feita conforme o indicado pela maioria dos critérios.

Quando as variáveis são cointegradas, a relação entre elas pode ser expressa como um mecanismo de correção de erro (MCE). Na prática, o mecanismo consiste em incorporar os choques de curto prazo ao modelo VAR. Desse modo, pode-se especificar um modelo VEC da seguinte forma:

$$
\Delta X_{t}=\Phi_{0}+\Phi X_{t-1}+\sum_{j=1}^{p-1} \Pi_{j} \Delta X_{t-j}+e_{t}
$$

em que $\Phi_{0}$ é um vetor $n \times 1$ de constantes; quando há raiz unitária, $\Phi=\alpha \beta$, em que $\alpha$ é a matriz de ajustamento com $r$ vetores de ajustamento e $\beta$ é uma matriz que contém $r$ vetores de cointegração; e $X$ é um vetor composto pelas variáveis endógenas YW, ER, IDE e EXP.

Após a estimação do modelo mais adequado (VAR ou VEC), será analisada a causalidade de Granger. As relações de interdependência entre as variáveis a serem analisadas verificam se os valores defasados de uma determinada variável são úteis para explicar o valor corrente de outra variável, por meio do teste de causalidade de Granger (1969). Dizer que $z$ causa por Granger $y$ é equivalente a dizer que existe uma relação de precedência temporal entre elas.

Além do teste de causalidade, o modelo VAR também possibilita obter a decomposição da variância do erro de previsão, que informa o quanto a variância do erro de previsão de uma série é explicada pela própria série ou por outras séries, o que é um indicativo de causalidade entre as séries temporais.

Ao transformar o modelo VAR em um vetor média móvel (VMA) e promover a ortogonalização dos resíduos e diagonalizar a matriz de variância-covariância dos erros para verificar o efeito do choque em apenas uma variável sobre o sistema, pode-se obter a decomposição da variância do erro de previsão. ${ }^{3}$

\subsection{Dados}

Neste estudo, as séries de dados referentes às exportações agropecuárias brasileiras, exportações e importações mundiais (a soma dessas variáveis foram usadas como proxy para renda mundial) e taxa de câmbio real foram obtidas por meio do site do Ipeadata, sendo essas séries fornecidas a esse site, respectivamente, pela Fundação Centro de Estudos do Comércio Exterior (Funcex), pelo Fundo Monetário Internacional (a partir das International Financial Statistics) (FMI/IFS) e pelo Instituto de Pesquisa Econômica Aplicada (Ipea). Já a série de

3 Para mais detalhes acerca do teste de causalidade de Granger e da decomposição da variância do erro de previsão, consultar Granger (1969) e Enders (1995). 
dados referente ao ingresso de IDE no setor agropecuário brasileiro foi obtida no site do Banco Central do Brasil.

O período de análise do estudo compreende o intervalo de janeiro de 2001 a julho de 2011, sendo que os dados estão dispostos mensalmente. A escolha do período visa obter maior número de observações, e, por conseguinte, maior robustez dos resultados, e abarcar a significativa expansão do setor agropecuário brasileiro e da entrada de IDE na economia na última década. Por fim, é importante destacar que as séries utilizadas foram dessazonalizadas e estão expressas em dólares (US\$), da mesma forma que os valores FOB (free on board) das exportações e importações.

\section{Resultados}

Diante do procedimento indicado na metodologia, primeiramente, realizou-se o teste $\mathrm{ADF}$ para verificar a existência de raiz unitária em cada uma das quatro séries. Conforme os resultados dos testes indicados na Tabela 1, a hipótese nula, que indica a presença de uma raiz unitária, foi rejeitada para as séries em análise. Nesse sentido, todas as séries não possuem raiz unitária e, portanto, são estacionárias em nível [I (0)], a 1\% de significância.

Tabela 1 - Teste de raiz unitária ADF para séries YW, ER, Exp e IDE (jan. 2001 a jul. 2011)

\begin{tabular}{ccccccc}
\hline \multirow{2}{*}{ Variável } & \multirow{2}{*}{ Estatística } & Valor calculado & \multicolumn{3}{c}{ Teste ADF } & \multirow{2}{*}{ N.d. } \\
\cline { 3 - 5 } & & & $\mathbf{1 \%}$ & $\mathbf{5 \%}$ & $\mathbf{1 0 \%}$ & \\
\hline Renda (YW) & $\tau_{\tau}$ & -4.450 & -4.034 & -3.446 & -3.148 & 3 \\
Câmbio (ER) & $\tau_{\tau}$ & -4.090 & -4.033 & -3.466 & -3.148 & 2 \\
Exp & $\tau_{\tau}$ & -5.223 & -4.032 & -3.445 & -3.147 & 0 \\
IDE & $\tau \mu$ & -10.065 & -3.482 & -2.884 & -2.579 & 0 \\
\hline
\end{tabular}

Fonte: Elaboração própria a partir dos resultados da pesquisa.

Nota: $\tau=$ equação sem intercepto e sem tendência; $\tau \mu=$ equação com intercepto e sem tendência; $\tau_{\tau}=$ equação com intercepto e com tendência; $N . d .=$ número de defasagens.

O próximo passo consiste em verificar se as séries apresentam uma relação de equilíbrio de longo prazo, pois, de acordo com Johansen-Juselius (1990), variáveis não estacionárias em nível podem caminhar juntas por meio de uma trajetória temporal interligada, revelando, desse modo, a presença de cointegração entre si. No entanto, visto que todas as séries revelaram-se estacionárias em nível, não há necessidade de verificar a existência de cointegração entre elas. 
Nesse sentido, conforme exposto no referencial analítico, como as séries são estacionárias em nível I (0), os testes de causalidade e decomposição da variância do erro de previsão serão testados no contexto de um modelo VAR em nível, ou seja, o procedimento padrão. Dessa forma, primeiramente, procedeu-se a definição da ordem de defasagem do modelo VAR.

A análise dos resultados da Tabela 2 indica que o modelo VAR deve conter uma ou quatro defasagens, variando de acordo com o critério de informação observado. Neste estudo, optou-se pela inclusão de quatro defasagens, conforme indicado pela maioria dos critérios (LR, FPE e AIC), pois se acredita que quatro defasagens reflitam de forma mais adequada a dinâmica de relacionamento entre as variáveis econômicas em estudo.

Tabela 2 - Definição do número de defasagens do modelo VAR

\begin{tabular}{cccccc}
\hline Defasagens & LR & FPE & AIC & SC & HQ \\
\hline 0 & $\ldots$ & $1.79 \mathrm{E}+21$ & 60.28968 & 60.38161 & 60.32702 \\
1 & 786.9912 & $2.79 \mathrm{E}+18$ & 53.82555 & $54.28523^{*}$ & $54.01226^{*}$ \\
2 & 37.18941 & $2.62 \mathrm{E}+18$ & 53.75874 & 54.58615 & 54.09481 \\
3 & 27.64663 & $2.64 \mathrm{E}+18$ & 53.76739 & 54.96255 & 54.25283 \\
4 & $54.03162^{*}$ & $2.06 \mathrm{e}+18^{*}$ & $53.51510^{*}$ & 55.078 & 54.1499 \\
5 & 17.55599 & $2.27 \mathrm{E}+18$ & 53.60358 & 55.53421 & 54.38774 \\
\hline
\end{tabular}

Fonte: Elaboração própria a partir dos resultados da pesquisa.

Nota: (") indica a ordem de defasagem ótima de acordo com cada critério de informação: $L R=$ Likelihood ratio; FPE = Final prediction error; $A I C=$ Akaike information criterion; $S C=$ Schwarz criterion; $H Q=$ Hannan-Quinn.

Para validar o número de defasagem escolhido pelos critérios, procedeu-se ao teste de autocorrelação dos resíduos pelo multiplicador de Lagrange (LM). Os resultados da Tabela 3 indicaram que para quatro defasagens não se rejeita a hipótese nula de ausência de autocorrelação serial, corroborando, assim, a ordem de defasagem definida pelos critérios de informação. 
Tabela 3 - Teste de autocorrelação dos erros por LM

\begin{tabular}{ccc}
\hline Defasagem & Estatistica (LM) & Probabilidade \\
\hline 1 & 16.8251 & 0.3970 \\
2 & 35.4213 & 0.0035 \\
3 & 28.2435 & 0.0296 \\
4 & 19.7177 & 0.2332 \\
5 & 26.1101 & 0.0525 \\
6 & 18.1564 & 0.3148 \\
7 & 29.6761 & 0.0198 \\
8 & 21.1964 & 0.1711 \\
9 & 7.6353 & 0.9590 \\
10 & 4.9409 & 0.9960 \\
11 & 28.4801 & 0.0277 \\
12 & 7.7467 & 0.9561 \\
\hline
\end{tabular}

Fonte: Elaboração própria a partir dos resultados da pesquisa.

Diante de tal resultado, a estimação de um modelo VAR padrão com quatro defasagens é a mais adequada para prosseguir a análise de causalidade entre as variáveis estudadas. Desse modo, as relações de causalidade de Granger são apresentadas na Tabela 4.

Tabela 4 - Teste de causalidade de Granger

\begin{tabular}{lll}
\hline \multicolumn{1}{c}{ Variáveis } & Qui-quadrado & Probabilidade \\
\hline Variável dependente: IDE & & \\
Câmbio & 1.584655 & 0.811 \\
Renda mundial & 11.40443 & $0.022^{* *}$ \\
Exportações & 8.339182 & $0.079^{* * *}$ \\
\hline Variável dependente: câmbio & & \\
IDE & 3.09656 & 0.542 \\
Renda mundial & 5.393373 & 0.249 \\
Exportações & 2.123722 & 0.713 \\
\hline Variável dependente: renda mundial & & \\
IDE & 6.946342 & 0.139 \\
Câmbio & 10.04418 & $0.039 * *$ \\
Exportações & 7.406543 & 0.116 \\
\hline
\end{tabular}




\section{Variáveis}

Qui-quadrado Probabilidade

Variável dependente: exportações

IDE

4.7432

0.315

Câmbio

5.191401

0.268

Renda mundial

10.85121

$0.028^{* *}$

Fonte: Elaboração própria a partir dos resultados da pesquisa.

Nota: $(* * *)$ rejeita-se a hipótese nula de não causalidade ao nível de 10\%; (**) rejeita-se a hipótese nula de não causalidade ao nível de 5\%; (*) rejeita-se a hipótese nula de não causalidade ao nível de $10 \%$.

Analisando os resultados do teste de causalidade, constata-se que a taxa de câmbio não é causada, no sentido de Granger, por nenhuma das variáveis em análise. No entanto, verifica-se que o câmbio causa a renda mundial, ou seja, a análise indica a rejeição da hipótese nula, a um nível de $5 \%$ de significância, de que a variável cambial não causa a renda mundial, no sentido de Granger.

Segundo Missio, Oreiro e Jayme Jr. (2011), o caminho pelo qual a taxa real de câmbio pode influenciar a renda mundial e o crescimento econômico, que é particularmente relevante para economias emergentes, é por intermédio dos efeitos do câmbio real sobre o grau de heterogeneidade estrutural dessas economias. A heterogeneidade estrutural refere-se aos desníveis tecnológicos e de produtividade dentro da estrutura produtiva, os quais resultam, em sua maioria, da insuficiência dinâmica do sistema, causada pelo baixo ritmo de acumulação de capital, pela adoção de tecnologias inadequadas e pelas disparidades da absorção da mão de obra disponível. Desse modo, ainda de acordo com Missio, Oreiro e Jayme Jr. (2011), a manutenção de um câmbio competitivo induz o investimento e uma mudança estrutural na economia e, portanto, a política cambial pode influenciar o crescimento por possibilitar, não apenas o aumento da competitividade de curto prazo, mas, também, por atuar no sentido de prover os incentivos necessários ao investimento e ao maior desenvolvimento tecnológico, o que implica na capacidade de influenciar as condições de oferta de longo prazo, provocando o crescimento econômico dos países e da renda mundial, por consequência.

Adicionalmente, os resultados empíricos do estudo de Razin e Collins (1997), que analisou a relação entre o desalinhamento cambial e o crescimento do produto real para uma amostra de 93 países desenvolvidos e em desenvolvimento no período 1975-1993, mostraram que, enquanto apenas sobrevalorizações muito intensas da taxa real de câmbio estão associadas ao crescimento econômico mais lento no longo prazo, subvalorizações moderadas do câmbio real têm efeito positivo sobre o crescimento do PIB das economias e, consequentemente, da renda mundial. Ademais, Frenkel (2004), ao analisar a performance do emprego e da taxa de crescimen- 
to de países emergentes, constatou que a manutenção de uma taxa real de câmbio competitiva e estável é a melhor contribuição que a política macroeconômica pode dar ao crescimento econômico de longo prazo.

Na sequência da análise da Tabela 4, observa-se que a renda externa causa, por Granger, as exportações agropecuárias brasileiras a um nível de 5\% de significância. Além disso, verifica-se que as exportações agrícolas do Brasil causam o ingresso de IDE no agronegócio brasileiro, que também é causado pela renda mundial, todas as causalidades no sentido de Granger. Dessa forma, pode-se inferir, em conformidade com a hipótese do trabalho, que o investimento externo no agronegócio brasileiro não tem impactado as exportações do setor. Por outro lado, observa-se que as exportações, desse mesmo setor, têm sido influenciadas pela renda externa e pelo impacto indireto da taxa de câmbio, uma vez que a influência do câmbio é causada por meio de seus efeitos sobre a renda mundial.

Com isso, verifica-se que o câmbio e a renda externa são de grande importância para a explicação de variações nas exportações agropecuárias brasileiras, uma vez que condições externas favoráveis em adição com uma taxa de câmbio atraente para os importadores podem elevar as exportações setoriais brasileiras e, em caso contrário, ocasionar uma queda no volume exportado pelos diversos setores.

Castro e Cavalcanti (1997), analisando as exportações da economia brasileira e utilizando metodologia semelhante, também obtiveram como resultado que, em geral, a renda mundial e a taxa de câmbio afetaram o nível de exportações totais, sendo a primeira variável mais influente. De acordo com os autores, as exportações de manufaturados foram mais sensíveis à renda e ao câmbio que as exportações totais, enquanto que as exportações de semimanufaturados dependeram apenas da renda mundial, e a de básicos, apenas da taxa de câmbio. Adicionalmente, o estudo de Oliveira (2007), que avaliou os determinantes da competitividade das exportações brasileiras, encontrou resultados que indicaram o câmbio e a demanda externa setorial como importantes determinantes das exportações setoriais brasileiras analisadas.

Já em relação aos resultados do teste de causalidade para o IDE como variável dependente (Tabela 4), verifica-se que as exportações agropecuárias brasileiras e a renda mundial causam, no sentido de Granger, o ingresso de capital estrangeiro no setor agropecuário do Brasil. Desse modo, por não haver uma causalidade bilateral entre o IDE e as exportações do setor agrícola, pode-se dizer que o grande volume exportado pelo setor atrai o capital externo, porém este não impacta as exportações agrícolas.

Esse fato também foi constatado em trabalho realizado por Fernandes (2006) que, ao analisar os setores da economia brasileira, concluiu, de modo geral, que o IDE não contribuiu para elevar as exportações domésticas, pois o seu ingresso esteve voltado, principalmente, para o mercado interno. Além disso, a autora destaca que os fluxos de IDE não geraram, diretamente, aumentos da capacidade de produção 
e de exportação da economia nacional, tratando-se, muito mais, de um processo de transferência patrimonial. Deve-se destacar, também, o estudo de Procópio, Fernandes e Silva (2010), que, ao avaliarem a entrada de IDE no setor do agronegócio brasileiro, verificaram que a maior parte do fluxo de IDE destinou-se às filiais estrangeiras caracterizadas pelo déficit e o baixo nível comercial com o exterior, levando à conclusão, pelos autores, que o IDE não contribuiu efetivamente para a melhoria das exportações do setor.

Os sentidos da causalidade de Granger podem ser melhor visualizado na Figura 1.

Figura 1 - Sentido da causalidade de Granger entre as variáveis analisadas no estudo

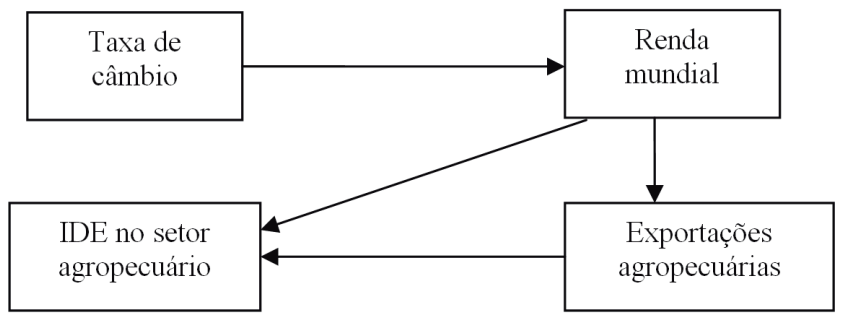

Fonte: Elaboração própria a partir dos resultados da pesquisa.

O teste de Granger permite, ainda, estabelecer o ordenamento das variáveis de acordo com a sua exogeneidade. Assim, segundo as estatísticas $X^{2}$ do teste, constata-se que a variável taxa de câmbio é a variável mais exógena, seguida pelas exportações agropecuárias brasileiras, depois a renda mundial e, por fim, pelo investimento externo no agronegócio nacional, que é a variável mais endógena do modelo.

Dada a existência das relações de causalidade verificadas entre as variáveis, torna-se oportuno verificar a decomposição histórica da variância do erro. Esse teste informa o quanto a variância do erro de previsão de uma série é explicada pela própria série ou por outras séries, o que é um indicativo de causalidade entre as séries temporais (ENDERS, 1995).

Conforme apresenta a Tabela 5, a decomposição da variância do erro de previsão para a taxa de câmbio é explicada em grande proporção por choques dados em si mesma, não havendo reação em grande medida a choques nas demais variáveis. Com relação à renda mundial, é possível inferir que no primeiro ano sua variância do erro de previsão é explicada em sua quase totalidade por ela mesma, mas, já no segundo mês, $7,2 \%$ dessa variância é explicada por choques na variável taxa de câmbio, que manteve um comportamento crescente nos períodos seguintes. Tal resultado corrobora a causalidade encontrada pelo teste de Granger, porém, diferentemente de tal teste, nesse caso as exportações apresentaram uma participação razoável na explicação da variância da renda externa, a partir do segundo ano. 


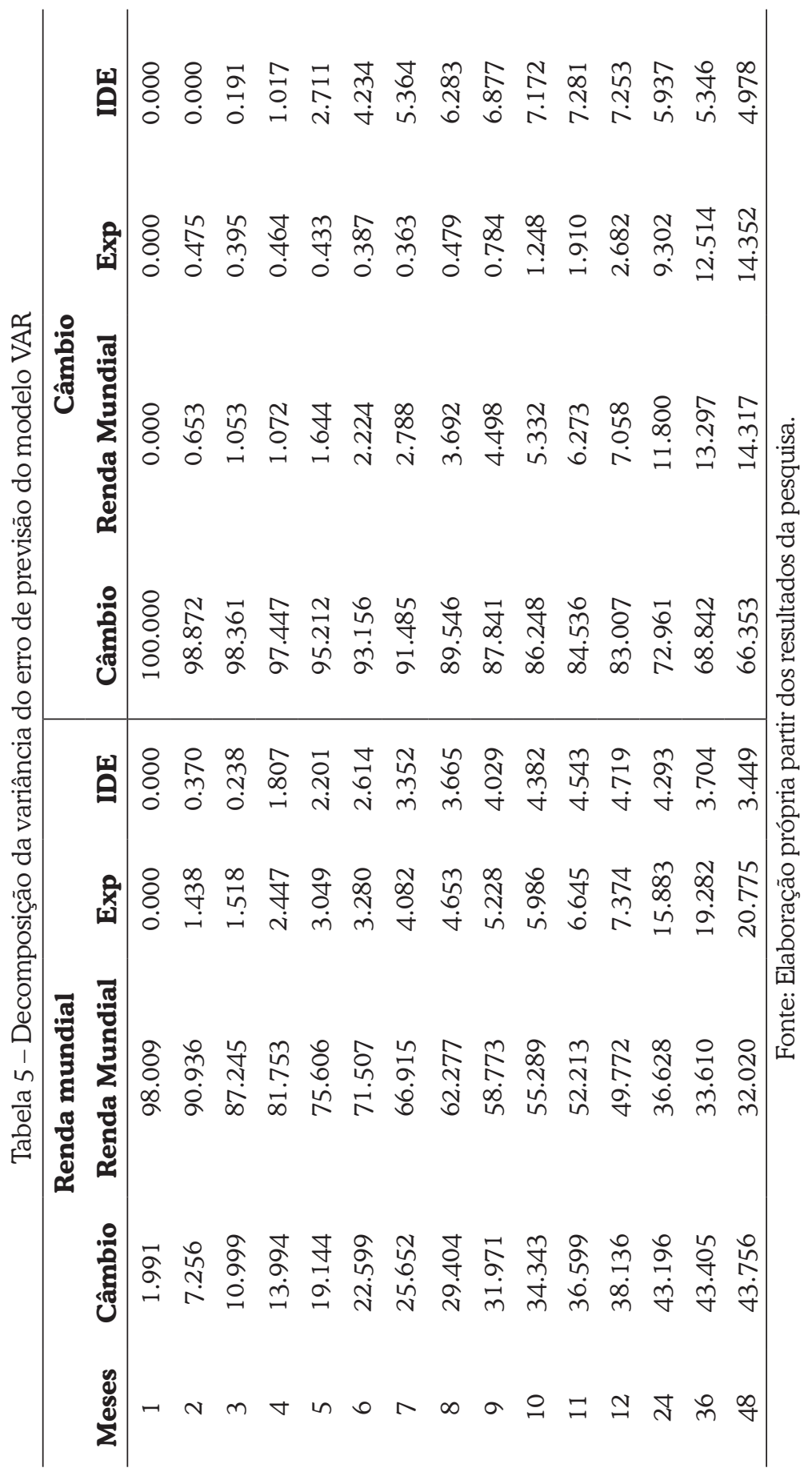

BITTENCOURT, G. M. ; CAMPOS, A. C. Determinantes das Exportações Agropecuárias... 
Na Tabela 6 são apresentadas as decomposições da variância do erro de previsão para o IDE e para as exportações do agronegócio. Sobre o investimento estrangeiro na agropecuária brasileira, verifica-se que a variação do seu erro de previsão é explicada, principalmente, por choques em si mesmo e por participações menores da renda mundial e das exportações do setor.

Tabela 6 - Decomposição da variância do erro de previsão do modelo VAR

\begin{tabular}{ccccc|cccc}
\hline Meses & Câmbio & $\begin{array}{c}\text { IDE } \\
\text { Renda } \\
\text { Mun- } \\
\text { dial }\end{array}$ & Exp & IDE & Câmbio & \multicolumn{4}{c}{$\begin{array}{c}\text { Exp } \\
\text { Renda } \\
\text { Mun- } \\
\text { dial }\end{array}$} \\
\hline 1 & 0.670 & 3.183 & 0.018 & 96.129 & 0.786 & 8.818 & 90.396 & 0.000 \\
2 & 0.698 & 3.093 & 5.203 & 91.006 & 1.343 & 6.848 & 89.090 & 2.719 \\
3 & 0.768 & 3.113 & 6.020 & 90.099 & 1.134 & 5.885 & 90.324 & 2.657 \\
4 & 0.796 & 6.570 & 6.606 & 86.028 & 1.049 & 9.236 & 87.373 & 2.342 \\
5 & 0.927 & 6.612 & 6.611 & 85.851 & 1.025 & 8.833 & 87.383 & 2.758 \\
6 & 0.927 & 7.302 & 6.559 & 85.212 & 1.175 & 9.692 & 85.892 & 3.241 \\
7 & 1.016 & 8.314 & 6.868 & 83.802 & 2.157 & 11.675 & 83.127 & 3.042 \\
8 & 1.132 & 8.379 & 6.864 & 83.625 & 3.939 & 11.843 & 81.177 & 3.041 \\
9 & 1.256 & 8.917 & 6.841 & 82.986 & 6.187 & 13.279 & 77.706 & 2.828 \\
10 & 1.486 & 9.247 & 6.889 & 82.378 & 9.027 & 14.410 & 73.966 & 2.597 \\
11 & 1.786 & 9.261 & 6.913 & 82.040 & 12.060 & 14.793 & 70.728 & 2.419 \\
12 & 2.109 & 9.496 & 6.933 & 81.461 & 14.856 & 15.847 & 66.988 & 2.309 \\
24 & 3.907 & 9.579 & 7.521 & 78.993 & 30.079 & 19.453 & 48.025 & 2.442 \\
36 & 4.416 & 9.762 & 7.888 & 77.934 & 33.959 & 20.175 & 43.558 & 2.308 \\
48 & 4.938 & 9.932 & 8.144 & 76.986 & 35.852 & 20.594 & 41.311 & 2.242 \\
\hline
\end{tabular}

Fonte: Elaboração própria a partir dos resultados da pesquisa.

Por fim, analisando os resultados para exportações, na Tabela 6 observa-se que, já no primeiro mês, a variável renda externa representa parte importante da decomposição da variância das exportações agrícolas. Por outro lado, em conformidade com o teste de causalidade de Granger, o IDE não apresentou participação na explicação da variância do erro de previsão das exportações no primeiro mês e manteve-se em valores baixos após o segundo período. Já a variável câmbio, a partir do décimo mês, passa a explicar proporção relevante da variância do IDE. Este último resultado corrobora a constatação sobre a influência indireta da taxa de câmbio nas exportações por meio de seus efeitos sobre a renda mundial. 


\section{Considerações Finais}

O contexto de expansão da economia mundial, o concomitante crescimento das exportações agropecuárias brasileiras, a variação da taxa de câmbio e o elevado ingresso de capital estrangeiro no Brasil e no setor agroexportador do país na última década foram os principais fatores responsáveis pela motivação de se verificar as relações de interdependência entre eles, além de possibilitar a verificação de quais variáveis realmente têm influenciado o desempenho das exportações agrícolas brasileiras.

De acordo com os resultados obtidos pelo estudo pode-se concluir que a hipótese testada, de que os fluxos de IDE não geraram aumentos na competitividade e na capacidade de exportação de produtos do agronegócio brasileiro e que o crescimento da economia mundial na última década foi o principal contribuinte para a elevação dessas exportações, foi aceita. Desse modo, por não haver uma causalidade bilateral entre o IDE e as exportações do setor agrícola, pode-se dizer que o grande volume exportado pelo setor atrai o capital externo, porém este não tem impactado as exportações agrícolas.

Adicionalmente, os resultados permitem observar que as exportações agrícolas respondem rapidamente a choques dados na renda externa, o que representou parte importante da variância dessas exportações. Ademais, observa-se que o IDE no setor não obteve participação relevante e que a variável câmbio, por meio de seus efeitos sobre a renda mundial, apresentou influência indireta sobre as exportações agropecuárias.

É importante ressaltar que a contribuição deste trabalho diferencia-se dos demais na literatura precedente ao realizar uma análise mais desagregada, pois trata do setor agropecuário em específico, o que evita a omissão das particularidades setoriais que ocorre em trabalhos que tratam de fluxos comerciais totais. Além disso, deve-se destacar a metodologia utilizada (modelagem VAR), a qual proporcionou uma análise completa e adequada para averiguação dos determinantes das exportações agropecuárias brasileiras.

Por fim, os resultados deste estudo apontam para uma maior atenção do governo brasileiro em relação ao destino do capital estrangeiro entrante no setor agropecuário, para que, dessa forma, os investimentos externos voltados para a criação de infraestrutura e novas unidades produtivas sejam priorizados, levando um maior impacto sobre as exportações desse setor e proporcionando um maior aproveitamento das oportunidades geradas pela expansão da economia mundial.

Para futuras extensões deste trabalho, sugere-se uma desagregação ainda maior dos dados do setor agropecuário, como também a análise das exportações de outros setores relevantes no comércio internacional brasileiro. 


\section{Referências}

BANCO CENTRAL DO BRASIL. Sistema de séries temporais. Disponível em: <http://.www.bc.gov.br>. Acesso em: 10 out. 2011.

BARROS, G. S. C.; BACCHI, M. R. P.; BURNQUIST, H. L. Estimação de equações de oferta de exportação de produtos agropecuários para o Brasil (1992/2000). Brasília, DF: IPEA, mar. 2002. (Texto para discussão $n^{\circ} 865$ ).

BIBLIOTECA NACIONAL DE AGRICULTURA. Dados estatísticos. Disponível em: $<$ http://www.agricultura.gov.br>. Acesso em: 10 out. 2010.

BIELSCHOWSKY, R.; STUMPO, G. A internacionalização da indústria brasileira: números e reflexões depois de alguns anos de abertura. In: BAUMANN, R. (Org.). O Brasil e a economia global. Rio de Janeiro: Campus, 1996.

BRASIL. Ministério do Desenvolvimento, Indústria e Comércio Exterior. SECRETARIA De Comércio Exterior. Dados estatísticos. Disponível em:

<http://www.desenvolvimento.gov.br>. Acesso em: 10 out. 2011.

BUCKLEY, P. J.; CASSON, M. The optimal timing of a foreign direct investment. Economic Journal, v. 91, n. 361, p. 75-87, Mar. 1981.

BUENO, R. D. L. S. Econometria de séries temporais. São Paulo. Cengage Learning, 2008.

CASTRO, A. S.; CAVALCANTI, M. A. F. H. Estimação de equações de exportação e importação para o Brasil: 1955/95. Rio de Janeiro: Ipea, 1997. (Texto para discussão, n. 469).

CAVALCANTI, M. A. F. H.; RIBEIRO, F. H. As exportações brasileiras no período 1977/96: desempenho e determinantes. Rio de Janeiro: Ipea, 1998. (Texto para discussão, n. 545).

CHADDAD, F. R. et al. Repensando as políticas agrícola e agrária do Brasil. Revista Digesto Econômico, v. 62, n. 400 , p. 6-45, nov./dez. 2006.

DUNNING, J. H. Explaining international production. London: London Unwin Hyman, 1988.

ENDERS, W. Applied econometric time series. New York: John Wiley, 1995.

FARINA, E. M. M. Q.; VIEGAS, C. A. S. Foreign direct investment and the Brazilian food industry in the 90s. International Food and Agribusiness Management Review, v. 5, n. 2, p. 1-16, 2003.

FERNANDES, E. A. Investimento direto externo no Brasil: efeitos no crescimento, nas exportações e no emprego. 2006. 143 f. Tese (Doutorado em Economia Aplicada) - Centro de Ciências Agrárias, Departamento de Economia Rural, Universidade Federal de Viçosa, Viçosa, 2006.

FLACH, L. Uma análise em modelo gravitacional para os determinantes do investimento direto externo no Brasil. 2004. 99 f. Monografia (Graduação em Economia) - Centro Socioeconômico, Departamento de Ciências Econômicas, Universidade Federal de Santa Catarina, Florianópolis, 2006. 
FRENKEL, R. Real exchange rate and employment in Argentine, Brazil, Chile and México. Buenos Aires: Centro de Estúdios de Estado y Sociedad, 2004. Mimeo.

GRANGER, A. Investigating casual relationship by econometric models and cross spectral methods. Econometrica, v. 37, p. 424-458, 1969.

GUEDES, A. A. Controle estrangeiro do setor sucroalcooleiro deve se acentuar. Luis Nassif Online, 6 jan. 2012. Disponível em:

<www.advivo.com.br/comentario/re-fora-de-pauta-34085>. Acesso em: 10 jan. 2012.

HIRSCH, S. An international trade and investment theory of the firm. Oxford Economic Papers, v. 28, n. 2, p. 258-270, July 1976.

INTERNATIONAL MONETARY FUND. Global financial stability report. 2008. Disponível em: < http://www.imf.org/external/pubs/ft/gfsr/2008/02/index.htm>. Acesso em: 10 nov. 2008.

JOHANSEN, S.; JOSELIUS, K. Maximum likelihood estimation and inference on cointegration with application to the demand for money. Oxford Bulletin of Economics and Statistics, v. 52, p. 169-209, 1990.

LIMA JR., A. J. M.; JAIME JR., F. Investimento direto estrangeiro e implicações macroeconômicas no Brasil. Análise Econômica, Porto Alegre, v. 26, n. 49, p. 87-114, 2008.

LIMA JÚNIOR, A. J. M. Determinantes do investimento direto estrangeiro no Brasil. 2005. 81 f. Dissertação (Mestrado em Desenvolvimento e Planejamento Regional) - Programa de Pós-Graduação em Desenvolvimento e Planejamento Regional, Faculdade de Ciências Econômicas, Universidade Federal de Minas Gerais, Belo Horizonte, 2005.

MARKAWALD, R.; RIBEIRO, F. Análise das exportações brasileiras sob a ótica das empresas, dos produtos e dos mercados. Revista Brasileira de Comércio Exterior, Rio de Janeiro, v. 19, n. 85, p. 3-20, out.-dez. 2005.

MISSIO, F. J.; OREIRO, J. L.; JAYME JR., F. G. Câmbio, crescimento e heterogeneidade produtiva num modelo keynesiano-estruturalista. In: ENCONTRO INTERNACIONAL DA ASSOCIAÇÃO KEYNESIANA BRASILEIRA, 4., 2011, Rio de Janeiro. Anais... Rio de Janeiro: Associação Keynesiana Brasileira, 2011.

NAKANO, Y. Globalização, competitividade e novas regras de comercio mundial. Revista de Economia Política, São Paulo, v. 14, n. 4, p. 7-31, 1994.

OLIVEIRA, S. C. S. Determinantes da competitividade das exportações brasileiras agregadas e setoriais: uma análise VAR (2000-2006). 2007. 116 f. Dissertação (Mestrado em Economia) Faculdade de Ciências Econômicas, Universidade Federal da Bahia, Salvador, 2007.

PINHEIRO, A.; HORTA, M. A competitividade das exportações brasileiras no período 1980/88. Pesquisa e Planejamento Econômico, Rio de Janeiro, v. 22, n. 3, p. 437-474, 1992.

PROCÓPIO, D. P.; FERNANDES, E. A.; SILVA, F. C. C. O Impacto do investimento direto estrangeiro no agronegócio brasileiro. In: CONGRESSO DA SOCIEDADE BRASILEIRA DE ECONOMIA ADMINISTRAÇÃO E SOCIEDADE RURAL, 48. , 2010, Campo Grande. Anais... Brasília, DF: Sober, 2010. 
RAZIN, O.; COLLINS, S. Real exchange rate misalignments and growth. Cambridge, MA: National Bureau of Economic Research, 1997. (NBER Working Paper, n. 6174).

RODRIGUES, L. A.; REIS, M. N. C.; MATTOS, L. B. Relações entre crescimento econômico, exportações e investimento direto estrangeiro no Brasil. Análise Econômica, Porto Alegre, v. 30, n. 58, p. 149-166, 2012.

RUGMAN, A. et al. International business: firm and environment. New York: McGraw-Hill, 1985.

SCHWANTS, F. et al. Determinantes da balança comercial do agronegócio brasileiro no período de 1990 a 2007: o agronegócio brasileiro e o comércio internacional. Curitiba: CRV, 2009.

SILVA, C. A. G.; FERREIRA, L. R.; ARAÚJO, P. F. C. O impacto do câmbio e da renda mundial nas exportações agropecuárias brasileiras. In: CONGRESSO DA SOCIEDADE BRASILEIRA DE ECONOMIA ADMINISTRAÇÃO E SOCIEDADE RURAL, 45., 2007, Londrina. Anais... Brasília, DF: Sober, 2007.

SIMS, C. A. Macroeconomics and reality. Econometrica, v. 48, p.1-48, 1980.

Recebido em: 06/10/2012. Aceito em: 04/09/2013. 